\title{
From care packages to Zoom cookery classes: youth work during the COVID-19 "lockdown"
}

\author{
Aileen Shaw, Bernadine Brady and Patrick Dolan
}

\begin{abstract}
Purpose - This paper aims to explore the experience of one large Irish youth work organisation, Foróige, to measures introduced during the initial phase of COVID-19 in 2020. In the face of the unprecedented crisis including the closure of schools and curtailment of many youth services, this paper examines how the organisation responded and adapted its service offering

Design/methodology/approach - Qualitative semi-structured interviews were conducted with 12 senior managers and youth officers in Foróige to explore their perspectives on the organisation's response. Participants were purposively sampled from across the operational management functions and also from regional levels and youth workers engaging in work "on the ground".

Findings - Shifting from a face-to -face, relationship-based to a distanced mode of engagement with young people, colleagues and volunteers required significant adaptation of Foróige's service model. Innovation took place both in the delivery platform and fundamentally, in its service orientation. The accelerated move to online youth work brought about by the pandemic enabled the organisation to embrace and learn from the challenges and opportunities posed by digital technology. Responding to the immediate and tangible needs of young people in receipt of services, staff found themselves working with families at the more basic levels of intervention.
\end{abstract}

Originality/value - This paper provides new insights into the nature of non-profit service innovation during a time of unprecedented crisis management. It highlights characteristics of organisational agility that can assist organisations in managing crises, while also pointing the way towards a more flexible operating model for youth work service delivery.

Keywords Ireland, Service innovation, Youth work, COVID-19, Non-profit crisis management, Online youth work

Paper type Research paper

\section{Introduction}

The COVID-19 pandemic "placed the greatest restrictions on the lives of children seen in modern times" (Crushell et al., 2020, p. 8). Commencing in Spring 2020, the widespread closure and disruption of schools, universities and educational services, the shutting down of statutory services and the curtailment of physical and recreational outlets has had a considerable impact on all aspects of life and society. While much of the focus in public discourse and research has been on the impact of school closures, youth work organisations were also forced to shut their doors as part of the COVID-19 restrictions. In responding to the COVID-19 pandemic, youth work organisations globally have been confronted with a set of unforeseen and unprecedented circumstances (OECD, 2020). The pandemic fits the categorisation of a crisis defined within the non-profit literature as a specific, unpredicted event or series of events that carries a high degree of threat to the delivery of an organisation's goals (Seeger et al., 2003; Coombs, 2012).
Aileen Shaw, Bernadine Brady and Patrick Dolan are all based at the School of Political Science and Sociology, National University of Ireland Galway, Galway, Ireland.
Received 28 June 2021 Revised 21 December 2021 Accepted 7 February 2022

(c) Aileen Shaw, Bernadine Brady and Patrick Dolan. Published by Emerald Publishing Limited. This article is published under the Creative Commons Attribution (CC BY 4.0) licence. Anyone may reproduce, distribute, translate and create derivative works of this article (for both commercial and non-commercial purposes), subject to full attribution to the original publication and authors. The full terms of this licence may be seen at http://creativecommons. org/licences/by/4.0/legalcode 
While it can take many forms, youth work is generally understood as non-formal education activity that takes place in youth clubs, community centres or on the streets with the aim of promoting personal and social development and social inclusion for young people (Brady et al., 2020). A core aim of youth work is to work with the young people "so that they might better relate to themselves, others and the world" (Jeffs and Smith, 2010, p. 3). For young people, youth work has been found to offer an enjoyable sanctuary from the pressures and demands of family, school and neighbourhood, providing a place "where workers care and young people are valued, respected and have choice" (Jeffs and Smith, 2010, p. 5; Moran et al., 2018). It is also an arena for personal and social development and a means through which young people can connect with their communities. The development of "meaningful, productive relationships" between the youth worker and the young person is considered "the essential ingredient" of successful youth work (Blacker, 2010, p. 30).

In several respects, the closure of schools and services as a result of the pandemic elevated the role of youth organisations. Evidence suggests that the pandemic is most likely to negatively affect marginalised groups and that pre-existing social and economic inequalities will be exacerbated as a result (Darmody et al., 2020; DCYA and Spunout, 2020; Erwin and Thompson, 2020). An OECD (2020) report found that youth organisations swiftly acted to disseminate information and to mitigate the disruptions of the crisis. Many provided access to educational resources, peer-to-peer mental health advice and other programmes to support adolescents and young adults in confinement. The report found these initiatives have been crucial in mitigating the closure of schools and support services, addressing loneliness and anxiety and promoting social cohesion. More than half of organisations turned to digital and online tools to provide practical advice to young people on how to deal with mental and physical health, stigma and discrimination (OECD, 2020). However, sustaining involvement proved problematic. Research by Erwin and Thompson (2020) found that a majority of Irish youth organisations were able to maintain a service during the pandemic but experienced a significant drop in levels of engagement, particularly from marginalised young people.

It is of interest, therefore, to explore in greater detail how youth work organisations responded in the wake of service closures brought about by the COVID-19 pandemic and the measures taken to maintain a youth work service in this unique context. In Ireland and internationally, youth work services are delivered primarily by voluntary or non-profit organisations. While there will be common approaches and strategies adopted among nonprofit organisations to respond to a crisis, Millar (2010, p. 144) argues that because of the unique nature of youth work activity, youth work managers "cannot simply import management models from other industries". The management characteristics required in youth work organisations include a commitment to listening and responding to young people, encouraging entrepreneurship and autonomy, being open to partnership and being responsive to change. This paper explores how one large Irish youth work organisation, Foróige responded and adapted during the initial period of COVID-19 closures, an experience resonant with youth serving organisations in other jurisdictions.

\section{Youth work and voluntary sector management during a crisis}

While the environment in which youth work takes place is constantly changing as a result of policy, technological, economic and social changes (Millar, 2010), it can be argued that the scale of challenge posed by the COVID-19 pandemic is unprecedented in recent history. Within non-profits, a crisis is described by Jordan et al. (2016, p. 162) as "a time of disruption and change in the organisation's operating environment". Typically, the types of crises facing voluntary organisations include emergencies (natural or human-made disasters); controversies (internal financial mismanagement, staff or legal problems) and unanticipated occurrences beyond the normal range of experience (Patterson and Radtke, 2009; Jordan et al., 2016). In this regard, there are parallels with the nature of the crisis 
associated with the COVID-19 pandemic, the severity of which is impacting non-profit, forprofit and governmental sectors (Institute for Crisis Management, 2020).

In navigating a crisis of the scale and nature of the COVID-19 pandemic, two key strategies have been identified in the literature. Firstly, the ability of an organisation to innovate, and secondly, to adapt, namely, organisational agility. A study examining innovations associated with the COVID-19 pandemic introduced the concept of imposed service innovation (Heinonen and Strandvik, 2020, p. 108). The authors argue that a crisis such as COVID-19 accelerated strategic re-orientation and innovation within organisations out of necessity and should be viewed as "actions for resilience and renewal, rather than differentiation and growth".

McKinsey and Company (2020) identified five characteristics of organisational agility that organisations demonstrated in navigating COVID-19. Each characteristic not only assisted in managing the crisis, but also points the way toward a more "agile" operating model for the "next normal." These are as follows:

1. establishing a common purpose and clear communications;

2. setting up structures to enable rapid decision making, including the reallocation of resources against new priorities;

3. creating networks of local teams with clear, accountable roles;

4. developing a less hierarchical culture that empowers people and gives them the opportunity to unleash their entrepreneurial drive; and

5. providing people with the technology they need (McKinsey and Company, 2020).

\section{Context for the study}

In Ireland, Youth work is funded and regulated by the government but provided by an estimated 40 voluntary organisations of varying sizes throughout the country (Indecon, 2012). Foróige is Ireland's largest youth development organization, working with approximately 50,000 young people aged 10-20 nationally on youth education programmes complementary to home, school and work that enable the participation of young people in their own development and in society. Foróige has two models of youth work - Volunteer Services and Targeted Services. In 2019, over 5,700 people volunteered with the organisation, the majority of whom were involved in 577 locally based youth clubs throughout Ireland.

The organisation operates a range of targeted services, whereby education, training and development programmes are provided by professional youth workers, sometimes in partnership with adult volunteers, to young people experiencing particular disadvantage, risk or marginalisation. It also provides a variety of non-formal education programs, developed on the basis of international evidence (Brady and Redmond, 2017), including Leadership for Life and Network for Teaching Entrepreneurship and operates the Big Brother Big Sister mentoring programme in Ireland. The organisation employs approximately 350 staff, has a budget of just over $€ 27 \mathrm{~m}$ and is funded by government departments including the Department of Children and Youth Affairs, Education and Training Boards, the Health Service Executive, Irish Youth Justice Service and TUSLA (Foróige, 2020) .

\section{Methodology}

The impetus for this study came from the UNESCO Child and Family Research Centre. In response to the unprecedented nature of events, a member of the research team approached the CEO of Foróige to explore the possibility of documenting the experience of 
the organisation as one of the few services to remain in operation for young people during the initial COVID-19 crisis. An independent research team of three staff experienced in youth work practice, programme development and non-profit management undertook the study.

As this study aimed to understand the organisational response to an unprecedented phenomenon, a qualitative approach was chosen for its capacity to elicit rich descriptions and facilitate a deep understanding and interpretation of lived experiences (Castleberry and Nolen, 2018). In seeking to examine the rationale adopted by key decision-makers within Foróige in developing an immediate response to the crisis from individuals with indepth information, a purposive sampling approach was adopted. The underlying selection criteria concerned their direct experience of responding to the crisis and importantly their interaction with other stakeholders in the negotiation, implementation and assessment of the response. Participants were purposively sampled for their ability to provide a perspective from the levels of management and also from regional levels and from youth workers engaging in face to face work "on the ground". A sampling frame was drawn up to include the following categories: management, senior youth workers, programme directors, national and regional leads and with representation across gender, geography and staff grade. The organisation provided a listing of potential candidates according to these criteria. Of the 15 individuals approached by the research team, 12 agreed to participate.

Qualitative semi-structured interviews were conducted with 12 participants across the Foróige organisation to explore their perspectives on the organisations' initial response to the COVID-19 situation. Four of the sample identified as male and eight as female. Information sheets and consent forms were distributed and obtained from all participants, outlining the aim of the study, how the study would be conducted and the potential risks and benefits associated.

The interviews were conducted in May and June 2020 online using Zoom by three members of the research team and lasted between 30 and 50 minutes. Questions included the initial actions taken by Foróige, views on how young people responded, benefits and challenges associated with new ways of working and key learning for the organisation. Interviews were audio recorded, data was transcribed in full and transferred to QSR NVivo for analysis.

Data was analysed using a process of thematic analysis (TA) (Braun and Clarke, 2006). The transcripts were read in full by all three members of the research team codes were assigned to parts of the texts to identify similarities and differences in the data. Following discussion, a set of broad categories and sub-themes were identified. The entire data set was then re-read which resulted in greater refinement of categories and themes. In the end, five main categories were identified and the findings are presented under these headings. The analysis process concluded by a team approach to writing, using quotes to illustrate the points made.

There are a number of study limitations which must be acknowledged. While it can be seen as a strength of the study that it focusses on just one organisation, it is also a limitation, which means that we are unable to say if these experiences were shared by other youth organisations. This limitation is addressed by drawing on broader literature as much as possible. Secondly, the study is based on a small purposive sample of senior staff and managers and thus cannot be considered representative of the whole organisation. The study would have been strengthened had it also included the views of young people and volunteers.

\section{Findings}

The ethos of Foroige, shared among youth work organisations, is based on relationshipbased, interactive engagement with young people, particularly marginalised groups. As discussed below, shifting from a face-to-face mode to a distanced mode of engagement 
with young people, staff and volunteers required significant adaptation of Foróige's service model across all levels of the organisation. Innovation took place both in the delivery platform and fundamentally, in its service orientation. Our findings highlight a number of challenges associated with the accelerated move to online youth work brought about by the pandemic while also demonstrating the opportunities to embrace and learn posed by digital technology. Critically, the findings also highlight the priority accorded to addressing the immediate and tangible needs of young people in receipt of services as staff found themselves working with families at the more basic levels of intervention.

\subsection{Management response}

Following the announcement of the national "lockdown" on 12 March 2020 and the closure of youth services, Foróige's Senior Management Team (SMT) adopted a "crisis management" approach during which the team met virtually three times weekly. The primary concern at this stage related to how best to maintain the ethos of Foróige, an organisation fundamentally about the social development of young people through engagement and relationships, in the face of an unprecedented crisis. As one manager posed it, the glaring issue confronting the organisation was "how we could continue to support young people because it was absolutely against all of our instincts that we couldn't meet young people and families face-to-face." The SMT defined their strategy as:

- do no harm;

- concentrate on the most vulnerable young people; and

- reach out to as many young people as possible.

At an immediate level, the most significant challenge was "turning a face to face service into an online service within a matter of days". In facilitating this turnaround, Foróige, as a result of significant philanthropic investment, had a robust infrastructure with three foundational elements of a non-profit's capacity framework - systems and infrastructure, human resources and organisational structures - highly resourced (McKinsey and Company, 2001). This included information technology (IT) systems, hardware (encrypted laptops, smartphones) and in-house technical and professional expertise. Consequently, there was little delay in moving to remote working for the organisation's 350 staff.

However, staff had to adapt and learn quickly how to use online tools and platforms such as Google Hangouts and Zoom. A dedicated person was assigned as a conduit for the provision of information to staff and a COVID-19 section was established on the staff portal. This portal section served as an A-Z of across all areas of support from how to run meetings, what platforms to use, as well as hosting electronic records and enabling the sharing of tools and resources for online engagement. In addition, regular video messages were sent to staff and volunteers by the CEO and chairperson.

Early efforts focused on putting in place frameworks and structures to ensure the organisation had robust policies and procedures to support staff, volunteers, young people and their families to adapt to the new environment. With staff on the frontline, Foróige also had a duty of care to ensure that public health guidelines for hygiene and social distancing, contact tracing and so forth were communicated and deployed in line with government standards. New guidelines were required in a number of areas including how to work oneto-one remotely, how to do a home visit; existing policies such as online safety were reworked. Particular care was required to adapt child protection guidelines for remote working.

In the COVID-19 environment, Foróige staff members found themselves shifting from a face to face role to a distanced mode in their engagement with young people, colleagues and 
volunteers. At the same time, as outlined below, they were themselves experiencing personal difficulties:

Staff faced challenges in their own personal life, be it health issues, worries about vulnerable members of their family [...] and if they don't have their normal coping mechanisms, like any of us, being able to go for a pint or a game of football or whatever it might be. And when they're all taken away, it can really press down upon people when their coping mechanisms are taken. So, l'd say there's been a good cohort of staff who have struggled during it (the pandemic), just with their own life.

In this context, there was a need for flexibility in terms of supporting staff to do their jobs while also giving due regard to the stress staff were experiencing in adapting to the new circumstances.

\subsection{Consultation with young people and staff on the ground}

Among the immediate priorities of the organisation was the need to gather the views of young people with regard to their experiences of the "lockdown". An initial online consultation with the organisations' youth reference panel identified a number of concerns that surfaced with the closure of schools and curtailment of many services. These included fears about education, concerns for family members as well as a general sense of uncertainty and lack of information.

One youth worker described the issues that were identified on the ground as including lack of access to IT among disadvantaged young people and their families, as well as financial stress related to the economic shocks associated with the pandemic.

The lack of IT infrastructure that young people had. [...] in some houses, they might have to share a phone or share a laptop amongst a big family [...] [...] And then also where there's overcrowding or lack of structure, the timing of a Zoom call or a phone call at 11 o'clock could be difficult. [...] And then the other piece that came very quickly to our attention was families struggling and struggling financially, the change in either employment or the change in how payments were made to them, from weekly to bi-weekly.

The information derived from these consultations informed the organisations' response. For example, the sense of isolation reported by the young people convinced the organisation of the importance of moving its clubs and programmes online. Social media was identified as a key mechanism for continuing to engage with and connect with young people. Consultation with young people and staff on the ground became an ongoing priority.

\subsection{Stakeholder communication and engagement}

Early in the crisis, the SMT prioritised the need for a communications strategy to inform "who do we need to talk to, who do we need to influence and how best can we do that?" The CEO initiated contact with the government departments that provided core funding to the organisation, the majority of which was aligned with specific programmes and projects. Government officials were provided with weekly updates on issues arising for young people and the response of Foróige staff. In response, statutory funders demonstrated flexibility.

This concerted effort to bring stakeholders along included corporate and philanthropic funders as well as board members and advisory groups. Particularly at the outset of the crisis communication played an important role in providing reassurance to stakeholders about the direction and conduct of Foróige's response. With much of its revenue base aligned to programmatic funds, the need to access discretionary funding that could respond to issues arising for young people and their families emerged immediately. As described by one respondent, the day-to-day approach taken by the organisation developed largely as a response to practical realities facing families. Interviewees cited examples of requests from managers to access funds to pay for young peoples' food or 
phone credit, items of expenditure that would have been constrained under project budgets. The situation was exacerbated by the inflexible response of a European Union directive stating no use of programme funds could be directed to meet practical needs. As described by the interviewee below, staff encountered a lack of awareness of some stakeholders as to the severity of social and economic circumstances facing young people:

[...] (they) [...] couldn't understand why would we be going to family homes, why would we be talking to parents, didn't understand it so there's been a bit of a shake up and a wakeup call for people at that level as well in relation to the nature of the work we do in relation to the engagements we have and now it's an on-going piece of education as far as l'm concerned.

As a result of philanthropic and corporate support, Foróige availed of sponsorship with which to purchase phones, tablets and laptops distributed to and deemed necessary to maintain contact with young people.

\subsection{Reaching out to vulnerable young people and families}

During the pandemic "the net of who was vulnerable grew" and staff encountered more families with basic needs around food, hygiene products, phone credit and so on. While home visits would have previously been a minor part of Foróige's service, their importance escalated during the crisis. This increase in need for family support may have been due to other services having to step back. Home visits also served as a point of entry to reaching young people who did not respond to phone, text, WhatsApp or other overtures from staff. In addition, Foróige developed care packages for individual families. Along with the basics, such as food, hygiene products, phone or Wi-Fi credit, the packs delivered were tailored to the needs of the particular young person or family. Examples of materials in packs included activity books, arts and crafts materials and self-care products. Staff on the ground reported that care packages provided a good mechanism for engaging, not just with young people, but with their families and for gaining a picture of what was happening in the homes. The response from families was reported as hugely positive and with the experience translating into a sense "the connectivity with the families will stand to us in the long term as well."

A number of issues also emerged when the organisation tried to engage with some young people remotely. Issues with the home learning environment included access to electronic devices, quiet space to study and particularly in rural areas, connectivity. While the majority of young people had phones or access to broadband, difficulties emerged in sharing a phone or a laptop amongst large family households. A senior youth worker described a common scenario:

\footnotetext{
There's a family with six kids, they're living in a two-bedroom house and they're all on top of each other. So, how is Johnny or Michael supposed to be able to get on a computer and peace and quiet to do a Zoom chat with his youth worker, you know. On top of all the other stuff that's being put on them from schools, in some cases in social work, you know. So, those challenges also came to the fore quite quickly.
}

As a short-term emergency response measure, the organisation accessed philanthropic funding in order to provide laptops or devices to facilitate young people to continue schoolwork through online learning and to engage in Foróige programme activity. Priority was given to young people doing State exams or those staff deemed particularly vulnerable. One programme manager reflected that while some aspects of this outreach work will be maintained, the organisation will have to re-focus post-pandemic:

I've been in awe of some of our staff and what they have done to reach out and to engage and get into homes and to work and support families [...]. But I think we need to be very careful about pulling that back now - there was a time for that but we are youth work organisation, so we 
need to now funnel it back into doing the engagement with young people and try to bring back in those other services as well.

\subsection{Adapting youth work services for online delivery}

In terms of moving youth clubs, projects, programmes and training online, one Senior Youth Officer described how youth workers had no experience of online youth work so it took some time for a response to emerge:

So to put it in context, before Covid, we did no work online with young people, more or less [...] so a huge challenge for the staff has been how do you engage young people using methodology that you've never used before and that you've no training in? And that you've no real idea how to run.

As outlined earlier, Foróige runs a range of services including volunteer-led youth services, staff-led youth activities and projects and manualised education programmes. We now look at the experiences of each of these services in adapting to online delivery.

5.5.1 Volunteer-led youth clubs Foróige Clubs generally meet one night a week for one and half to two hours for 12 to 18 year olds and offer a safe, enjoyable place for young people to hang out, meet new friends, get involved in activities and have a voice in their local communities. They differ from professionally led youth projects, as they are run by the young people themselves, with support from volunteer adults, who are members of the local community. Overnight in March 2020, the 577 clubs around the country were forced to close. Approximately 120 clubs returned with online engagement but could accommodate fewer participants, with an average of 20 young people on a call compared to up to 50 in a club.

In practice, moving the Foróige clubs online proved challenging. As a volunteer-led model, engagement faltered as outlined below by a national manager:

We've to persuade volunteers and that has proved challenging. Whether it was the lack of technical ability of the volunteers, or I suppose a fear or a concern about not being able to run the technical side of that was a challenge.

Furthermore, some respondents pointed out that the Foróige club experience served a number of functions for young people. Physically attending a community centre on a weekly basis offered a reprieve from family or school-related issues as well providing a relaxed social outlet, with a sense of structure and familiarity. Trying to replace that with an evening Zoom group proved difficult as described below:

So you'd a group that came together on a Friday night, it might be, in effect, a group mixing young people from various different backgrounds. You had the medium of kicking football or whatever it might be. Now, if you bring that group together on an online basis and one of the core reasons they're attending is taken away and they're all looking at each other on a Zoom screen, it's not a recipe for success, really.

While the traditional club may have struggled in the transfer to online delivery, several staff noted that the possibility of online clubs provided a new opportunity for the organisation. While the previous operating model depended on the availability of voluntary leaders and numbers of young people in a community to come together collectively and form a club, online clubs would enable the organisation to overcome a fundamental geographical barrier. Staff welcomed the potential of the organisation to engage young people that would have previously been precluded and saw a particular scope for niche or special interest clubs, such as Harry Potter or film clubs.

5.5.2 Staff-led youth activities and projects: The experience of staff with regard to moving activities online was that it worked particularly well for structured, specific purpose activities. 
For example, the Foróige Reference Panel, a youth participation group of 64 young people elected from across the country, successfully moved all their meetings online. Staff reported that certain activities delivered in youth projects adapted well to Zoom including dance or cooking classes, coding or music, as well as quiz challenges. It was also felt that online engagement was preferred by some young people who previously struggled with social anxiety but did not appeal to others.

A programme manager reported that, that after an initial experience and the novelty factor, enthusiasm for Zoom waned:

But there's also, I think, a slight sense of fatigue with some of the young people. They've kind of done the Zoom thing, "Yeah, I don't want to do it again. Not interested." It is very stilted. It doesn't replace the face to face.

Across the spectrum of interviewees, participants emphasised the efforts that youth workers put in to developing creative methodologies for working with young people, to sharing them with colleagues and to the generous and adaptable ways in which staff gave time and responded to the situation. The experience of moving to online engagement prompted a number of reflections on the inherent strength of the organisation and the importance of interaction. While elements worked well, most participants believed that the experience served to underscore the value of personal contact:

Staff would be absolutely delighted and young people too, if things went back to normal tomorrow. They've adapted very well and they've worked very hard, but it's still been a struggle [... .]. It's just by the nature of the thing, we're not a technology organisation, so yeah, some of the stuff has worked pretty well, some hasn't and that's the reality of it.

5.5.3 Non-formal education programmes. As described earlier, Foróige runs a broad range of non-formal education programmes, (such as youth leadership, entrepreneurship, relationships and sexuality) which would mostly have been delivered face to face in youth projects, clubs and schools. While online delivery of programmes had been under consideration by Foróige, the pandemic provided the impetus to actually make it happen. One programme manager described how:

[...] we have talked about online learning, online programmes, online training for a long time and all of a sudden overnight we were forced to do it. So, it has accelerated things that we wanted to do in rapid speed and shown and proven that we can do this.

Staff from the organisations' training, learning and development department worked closely with programme staff on adapting content from face-to-face delivery to e-learning systems. The department worked rapidly to develop training, workshops, resources and other supports for programme facilitators and the wider staff team to ensure they were comfortable and competent to continue to work with young people in this new online environment.

\section{Discussion}

Emerging literature suggests that navigating a crisis of the scale and nature of the COVID-19 pandemic calls for a particular kind of response and one in which the ability of an organisation to innovate is critical. Non-profit innovation is typically associated with identifying new social needs and approaches (Murray et al., 2010; McDonald, 2007) that distinguish an organisation in the marketplace. Heinonen and Strandvik (2020) contrast the enforced response to the sudden and unforeseen disruption brought about by the pandemic with typical service innovations that are discretionary in nature. They argue that a crisis like COVID-19 accelerated innovation within organisations out of necessity. The case of Foróige has been discussed in the context of organisational agility and the adoption of new ways of working. The experience has implications both in terms of new operational and 
functional norms as well as the ethos and orientation for organisations delivering youth work services that are pertinent to organisations globally.

The study findings make it clear that the circumstances associated with the COVID-19 pandemic required significant adaptation of Foróige's service model. Across the organisation, innovation took place fundamentally, as an adjustment in service orientation and practically in the delivery platform (online). In the former, in responding to the immediate and tangible needs of young people in receipt of Foróige services, staff found themselves working with families at the more basic levels of intervention including the provision of care packages as well as supplying devices such as mobile phones and laptops. While the organisation operates a number of youth and family support programmes and services in communities, providing resources for families represented a new departure for the organisation. In response to the needs articulated by young people and staff on the ground, Foróige made "being there" for young people and families, particularly the most vulnerable, during the crisis a key priority. The adaptability and flexibility of staff and funders in resourcing and meeting basic, immediate needs was viewed as critical. A strength of voluntary youth organisations relative to statutory services is that they generally have greater flexibility, which gives greater scope to be needs-led (Macmillan and Rees, 2019; Buchroth and Husband (2015). Participants believed that the presence of Foróige served a highly valuable function during a time when other services could not meet the needs of vulnerable young people with some expressing the view that the bonds forged with young people and families would lead to opportunities for future engagement. However, respondents also cautioned that this shift in orientation should not overtake the organisation's core mission focused on direct work with youth.

In responding to the identified needs above, the organisation adapted to the more dynamic modes of action required by the immediate and potentially ongoing circumstances brought about by the pandemic. Among the indicators of organisational agility identified as a key component of non-profit crisis management, the importance of collaborative, values-based leadership that steers away from hierarchical models has been highlighted (Seeger et al., 2003; Witmer and Mellinger, 2016; McKinsey and Company, 2020). In navigating COVID-19, McKinsey and Company (2020) argue that such characteristics not only assist organisations in managing the crisis, they also point the way toward a more flexible operating model for the "next normal." In our study attaching priority to and putting in place structures for youth participation, communication and relationship management emerged as critical factors. Research has shown evidence of better outcomes for children and young people when young people are heard and given a chance to participate in decisions that affect them (Jackson et al., 2020). Foróige's Youth Reference Panel was established to ensure that the views of young people in various services throughout the country can be heard and acted upon by the organisation. These structures proved particularly valuable in the content of the COVID-19 crisis, enabling the organisation to quickly access the experiences of young people on the ground. In addition to informing its own strategy, Foróige brought the issues raised to the attention of government and philanthropy, advocating and negotiating to achieve a more nuanced and timely policy response. Related to this, a communications strategy devised at the onset of the crisis served to inform stakeholders and critically funders, early on, of any need for changes in direction of services and to provide assurances of transparent and accountable practice. Such effective communication Coombs (2012) argues is required to protect an organisation's stakeholders, build trust and to maintain its public image.

The second key area of innovation was the move to online youth work. Given the primacy accorded to inter-personal, face-to-face relationships within youth work, organisations have faced challenges in adapting to the online world. In many respects, while the trend toward digital youth work is viewed as a way of opening up new spaces and places for youth, research has identified a number of gaps in the skills required including training and youth 
worker competencies that need to be considered Fernández-de-Castro et al. (2021). Whilst youth workers feel it is imperative that they move into online spaces (i.e. "respond or die" (Jaynes, 2020, p. 217), youth organisations have struggled in terms of finding a way to engage young people online, with lack of resources and fear of "boundary collapse" cited as key barriers (Chaskin et al., 2018; Jaynes, 2020). For Foróige, the accelerated move to online youth work brought about by the pandemic provided the opportunity to test out and learn from the potential for online youth work, something it had planned to embrace for some time.

As discussed earlier, consensus across interviewees was the online format worked well for specific groups or purposes. Structured, task focused groups where there were strong preexisting relationships and a clear sense of purpose or identity tended to translate well to an online setting. With support from staff, manualised programmes moved online quite successfully. At an individual level, the move to online working suited some young people, for example those who are quieter and previously may have struggled in face to face group work sessions. This reflects previous research which emphasises the social compensation potential of new technology, whereby those without strong networks or who are lonely or anxious often find it easier to connect with people online (Kivijärvi et al., 2019).

However, our study found the more informal, relationship based youth work, such as youth clubs and project activities did not transfer to the online format so successfully. Previous research has shown that young people value the relationships and sense of belonging and safety that arises from "hanging out" in youth spaces, such as projects and youth cafes (Brady et al., 2018). While communication via digital technology is an intrinsic aspect of contemporary youth culture, the ways in which young people use these media in their everyday lives is complex and regulated by the social norms of peer groups (Buckingham, 2009, Maclsaac et al., 2018). For example, Jaynes (2020) found that the use of social media platforms such as Snapchat were framed by young people as offering a refuge from parents and other authority figures and saw the youth centre as providing valuable time away from their devices. Some young people attend youth services, such as youth cafes as a means of escaping stressful or difficult home environments (Brady et al., 2018; Jeffs and Smith, 2010). Blacker (2010) notes that the environment in which youth work operates affects the possibilities for building and sustaining relationships. In line with these findings, it is possible that some young people do not see youth work as something they wish to do online. This is borne out by a survey of Irish youth work organisations, Erwin and Thompson (2020) found that while youth work organisations continued to provide a service online during the pandemic, engagement levels fell by $70 \%$.

Finally, in considering the potential for digital youth work, the issue of access, highlighted by the European Council Resolution on Smart Youth Work which called for attention to "mapping and addressing the digital gap and inequalities to access" emerged in this study as the greatest challenge for a youth work organisation aiming to work online with socially disadvantaged young people (Council of the European Union, 2017, p. 5). Research has consistently found that middle class homes more likely to have high spec computers and internet access than working class homes, with unequal access to the cultural and intellectual capital to use the technology effectively (France et al., 2020; Buckingham, 2009; OECD, 2020). While Foróige addressed issues of resourcing to help bridge this divide, these issues are deeply entrenched and pose a challenge to future online youth work strategies.

\section{Conclusion}

This paper has explored how one large Irish youth organisation adapted to the profound changes to their operating environment brought about by the COVID-19 crisis. Many of the themes from the literature on voluntary/non-profit crisis management were reflected in the strategies adopted. Significant service innovation and adaptation was undertaken, 
supported and enabled by proactive strategies to bolster organisational agility and responsiveness. The organisation's strategy was guided by ongoing communication with young people, staff, funders and government departments, which in turn necessitated advocacy, negotiation and relationship building. The needs of the most vulnerable young people and their families were addressed through the provision of practical and emotional support, while youth work clubs, groups and programmes were moved online. Heinonen and Strandvik (2020) argue that a crisis can act as a catalyst for a strategic re-orientation, transforming existing management strategies and accelerating critical reflection through challenging the underlying assumptions of the previous operating model. It is clear from this study that the experiences during this period will have a transformative effect on the future delivery of youth work services for the organisation.

Despite the stress associated with the onset of the pandemic, the experience of interviewees in this study point to a number of positives. The speed and agility of management in responding to needs and making the adjustments to operations and services, boosted confidence in the organisation, demonstrating the ability to deal with the unknown. The responses also revealed a sense of re-engagement with the value and the mission of the organisation as the crisis served to bolster staff morale in relation to the importance of youth work in society. In many ways, Foróige demonstrated resiliency. Resilience in non-profits, according to Witmer and Mellinger (2016) refers to the ability of an organisation to respond productively to significant disruptive change and transform the challenges into opportunities. The importance of hope and optimism that challenges are seen as surmountable is highlighted.

\section{References}

Blacker, I. (2010), "Relationships, friendship and youth work", in Jeffs, T. and Smith, M.K. (Eds), Youth Work Practice, Red Globe Press, London, pp. 15-30.

Brady, B. and Redmond, S. (2017), "Connecting research and practice: perspectives on the role of manualised programmes in youth work", Child \& Youth Services, Vol. 38 No. 3, pp. 252-268.

Brady, B., Forkan, C. and Moran, L. (2018), "Spaces of connection and belonging: young people's perspectives on the role of youth cafés in their lives", Child Care in Practice, Vol. 24 No. 4, pp. 390-401.

Brady, B., Chaskin, R.J. and McGregor, C. (2020), "Promoting civic and political engagement among marginalized urban youth in three cities: strategies and challenges", Children and Youth Services Review, Vol. 116, p. 105184.

Braun, V. and Clarke, V. (2006), "Using thematic analysis in psychology", Qualitative Research in Psychology, Vol. 3 No. 2, pp. 77-101.

Buckingham, D. (2009), "New media, new childhoods", in Kehily, M.J. (Ed.), An Introduction to Childhood Studies, Open University Press, Maidenhead, pp. 124-138.

Castleberry, A. and Nolen, A. (2018), "Thematic analysis of qualitative research data: is it as easy as it sounds?", Currents in Pharmacy Teaching and Learning, Vol. 10 No. 6, pp. 807-815.

Chaskin, R., McGregor, C. and Brady, B. (2018), Engaging Urban Youth: Community, Citizenship and Democracy. Research Report, UNESCO Child and Family Research Centre, Galway.

Coombs, W.T. (2012), Ongoing Crisis Communication: Planning, Managing and Responding, 3rd ed., Sage, Thousand Oaks, CA.

Council of the European Union (2017), "Council conclusions on smart youth work", Brussels, 3 November 2017 (OR. En) 13593/17.

Crushell, E. Murphy, J. and de Lacy, J. (2020), "National clinical review on the impact of COVID-19 restrictions on children and guidance on reopening of schools and the normalisation of paediatric healthcare services in Ireland", Health Service Executive, Dublin, available at: http://hdl.handle.net/ 10197/11619 (accessed 28 January 2021).

Darmody, M. Smyth, E. and Russell, H. (2020), "The implications of the Covid-19 pandemic for policy in relation to children and young people: a research review", Economic and Social Research Institute 
Research Series, Dublin, available at: www.esri.ie/system/files/publications/SUSTAT94_3.pdf (Accessed 28 January 2021)

DCYA and Spunout (2020), "How's your head? Young voices during covid-19: report of a national consultation with young people on mental health and wellbeing", DCYA, Dublin, available at: www.gov.ie/ en/publication/91f4b-hows-your-head-young-voices-during-covid-19-september-2020/ (Accessed 28 January 2021).

Erwin, D. and Thompson, L. (2020), "A review of the youth work sector response to the COVID-19 pandemic", National Youth Council of Ireland, Dublin, available at: www.youth.ie/documents/review-ofthe-youth-work-sector-response-to-the-Covid-19-pandemic/ (accessed 28 January 2021).

Fernández-de-Castro, P., Aranda, D., Moyano, S. and Sampedro, V. (2021), "Digital youth work: a systematic review with a proposal", Social Work Education, pp. 1-19, doi: 10.1080/02615479.2021.1971187.

Foróige (2020), "Annual report", available at: www.foroige.ie/about/publicationsannual-reviews (accessed 28 January 2021).

France, A., Coffey, J., Roberts, S. and Waite, C. (2020), Youth Sociology, Macmillan International: London.

Heinonen, K. and Strandvik, T. (2020), "Reframing service innovation: COVID-19 as a catalyst for imposed service innovation", Journal of Service Management, Vol. 32 No. 1, pp. 101-112.

Indecon (2012), "Assessment of the economic value of youth work", National Youth Council of Ireland, Dublin, available at: www.youth.ie/sites/youth.ie/files/Economic_Beneifit_Youthwork_2012.pdf (accessed 25 January 2021).

Institute for Crisis Management (2020), available at: https://crisisconsultant.com/Covid-19/ (accessed 28 January 2021).

Jackson, R., Brady, B., Forkan, C., Tierney, E. and Kennan, D. (2020), "Influencing policy and practice for young people in foster care: learning from a model of collective participation", Children and Youth Services Review, Vol. 113, p. 104901, doi: 10.1016/j.childyouth.2020.104901.

Jaynes, V. (2020), "'Befriend them but not be their friend': negotiations of youth practice in a digital age", Journal of Youth Studies, Vol. 23 No. 2, pp. 205-220, doi: 10.1080/13676261.2019.1592131.

Jeffs, T. and Smith, M.K. (2010), Youth Work Practice, Red Globe Press, London.

Jordan, T.A., Upright, P. and Tice-Owens, K. (2016), "Crisis management in nonprofit organizations: a case study of crisis communication and planning", The Journal of Nonprofit Education and Leadership Crisis Management in Nonprofit Organizations: A Case Study of Crisis Communication and Planning, Vol. 6 No. 2, pp. 159-177.

Kivijärvi, A., Aaltonen, S. and Välimäki, V. (2019), "The feasibility of an online discussion group as a component of targeted youth work in Finland", Children and Youth Services Review, Vol. 105, p. 104411.

McDonald, R. (2007), "An investigation of innovation in nonprofit organizations: the role of organizational mission”, Nonprofit and Voluntary Sector Quarterly, Vol. 36 No. 2, pp. 256-281.

McKinsey and Company (2001), Effective Capacity Building in Nonprofit Organisations, Venture Philanthropy Partners. Boston, MA.

McKinsey and Company (2020), "Agile resilience in the UK: lessons from COVID-19 for the 'next normal'", available at: www.mckinsey.com/business-functions/organization/our-insights/agile-resilience-in-the-uklessons-from-Covid-19-for-the-next-normal (accessed 28 January 2021).

Maclsaac, S., Kelly, J. and Gray, S. (2018), "'She has like 4000 followers!': the celebrification of self within school social networks", Journal of Youth Studies, Vol. 21 No. 6, pp. 816-835

Macmillan, R. and Rees, J. (2019), "Voluntary and community welfare", in Powell, M. (Ed.), Understanding the Mixed Economy of Welfare, Policy Press, Bristol, pp. 91-112.

Millar, G. (2010), "Managing and developing youth work".

Moran, L., Brady, B., Forkan, C. and Coen, L. (2018), “Individual and connected': an exploration of young people's discourses about youth cafes in Ireland", Journal of Youth Studies, Vol. 21 No. 8, pp. 1127-1139.

Murray, R., Caulier-Grace, J. and Mulgan, G. (2010), The Open Book of Social Innovation, National Endowment for Science, Technology and the Arts and the Young Foundation, London. 
OECD (2020), "Youth and COVID 19, response recovery, resilience", available at: www.oecd.org/ coronavirus/policy-responses/youth-and-Covid-19-response-recovery-and-resilience-c40e61c6/ (accessed 28 January 2021).

Patterson, S.J. and Radtke, J.M. (2009), Strategic Communications for Nonprofit Organizations: Seven Steps to Creating a Successful Plan, John Wiley \& Sons, Hoboken, New Jersey.

Seeger, M.W., Sellnow, T.L. and Ulmer, R.R. (2003), Communication and Organizational Crisis, Greenwood Publishing Group, Westport, CT.

Witmer, H. and Mellinger, M.S. (2016), "Organizational resilience: nonprofit organizations' response to change", Work, Vol. 54 No. 2, pp. 255-265.

\section{Further reading}

Central Statistics (CSO) (2020), "Social impact of COVID-19 survey", available at: www.cso.ie/en/ releasesandpublications/ep/p-sic19/socialimpactofCovid-19surveyapril2020/ (accessed 28 January 2021).

Coombs, W.T. (2002), "Deep and surface threats: conceptual and practical implications for 'crisis' vs 'problem'”, Public Relations Review, Vol. 28 No. 4, pp. 339-345.

Gilstrap, C.A., Gilstrap, C.M., Holderby, K.N. and Valera, K.M. (2016), "Sensegiving, leadership and nonprofit crises: how nonprofit leaders make and give sense to organizational crisis", VOLUNTAS: International Journal of Voluntary and Nonprofit Organizations, Vol. 27 No. 6, pp. 2787-2806.

Ritchie, J., Lewis, J., Nicholls, C.M. and Ormston, R. (Eds) (2013), Qualitative Research Practice: A Guide for Social Science Students and Researchers, Sage, London.

Seeger, M.W. (2006), "Best practices in crisis communication: an expert panel process", Journal of Applied Communication Research, Vol. 34 No. 3, pp. 232-244.

\section{Corresponding author}

Aileen Shaw can be contacted at: aileen.shaw@nuigalway.ie

For instructions on how to order reprints of this article, please visit our website: www.emeraldgrouppublishing.com/licensing/reprints.htm

Or contact us for further details: permissions@emeraldinsight.com 